\title{
ESTUDIAR ES ACTIVIDAD COMÚN EXTERNA Y SIEMPRE EDUCAMOS CON LA ACTIVIDAD. UNA APROXIMACIÓN DESDE LA PERSPECTIVA MESOAXIOLÓGICA
}

\author{
Studying is an external common activity \\ and we always educate with the activity. \\ An approach from the mesoaxiological perspective
}

José Manuel TOURIÑÁN LÓPEZ

Universidad de Santiago de Compostela. España.

josemanuel.tourinan@usc.es

https://orcid.org/0000-0002-7553-4483

Fecha de recepción: 27/04/2019

Fecha de aceptación: 27/05/2019

Fecha de publicación en línea: 05/09/2019

RESUMEN

Mesoaxiológica quiere decir comprender el medio valorado. Y en Pedagogía, la perspectiva mesoaxiológica significa comprender el medio valorado como educativo. Estudiar es una actividad y, en primer lugar, tiene valor pedagógico porque se usa para educar; es un medio para una finalidad especificada. Pero, además, estudiar tiene su propia finalidad, vinculada conceptualmente al término 'estudiar'; su finalidad es dominar-lograr saber aquello que se estudia. En perspectiva mesoaxiológica, no es lo mismo valorar la actividad de estudiar, porque es un medio para educar, que valorar la actividad de estudiar, porque la actividad en sí educa; es decir, no significa lo mismo para la Pedagogía decir que estudiamos para educarnos (para lograr finalidades educativas), que decir que, al ejecutar la actividad de estudiar, nos educamos. Si esa diferencia se significa, estudiar no solo tiene valor propedéutico, sino valor educativo en sí, porque la propia actividad de estudiar, al ser ejecutada, nos educa. En este caso, lo importante no es qué cosa estudio y cuál es la finalidad instrumental 
del estudio, sino que lo importante es la actividad misma de estudiar, porque me 'educo con' la actividad, al ejecutarla, y no solo por la meta educativa que persigo, sino por usar esa actividad.

Palabras clave: relación educativa; Pedagogía; fines de educación; medios de educación; valores educativos; relación medios-fines.

\section{ABSTRACT}

Mesoaxiological means to understand the valued mean. And in Pedagogy, the mesoaxiological perspective means understanding the mean valued as educational. Studying is an activity and, in the first place, it has pedagogical value because it is used to educate; it is a mean for a specified aim. But also, studying has its own aim, conceptually linked to the term 'study'; its purpose is to master-to know the one which is studied. In mesoaxiological perspective, it is not the same to value the activity of studying, because it is a mean to educate, that to value the activity of studying, because the activity itself educates; that is to say, it does not mean the same thing for Pedagogy to say that we study to educate ourselves (to achieve educational purposes), that to say that, when we execute the activity of studying, we educate ourselves. If that difference is meant, studying not only has propaedeutic value, but educational value in itself, because the very activity of studying, when It is executed, educates us. In this case, the important thing is not what matter I study and what is the instrumental purpose of the study, but what is important is the activity of studying itself, because I 'educate with' the activity, when I am executing it, and not only for the goal I pursue, but using that activity.

Key words: educational relationship; Pedagogy; sims of education; means of education; education values; means-ends relationship.

\section{INTRODUCCIÓN: ¿ESTUDIAMOS PARA EDUCARNOS O AL ESTUDIAR NOS EDUCAMOS? LA PERSPECTIVA MESOAXIOLÓGICA}

Mesoaxiológica quiere decir comprender el medio valorado. Y en Pedagogía, la perspectiva mesoaxiológica significa comprender el medio valorado como educativo. Para comprender la perspectiva mesoaxiológica, hay que centrar la reflexión en el significado de educación y su relación con la Pedagogía, que es conocimiento de la educación. Pedagogía mesoaxiológica quiere decir valorar como educativo cualquier medio utilizado para educar; significa hacer conocimiento teórico, tecnológico y práctico de la educación para valorar como educativo cualquier medio que se usa en la intervención pedagógica. Mesoaxiológica quiere decir comprender un medio valorado (en nuestro caso, desde la Pedagogía). La Pedagogía (el conocimiento de la educación) es mesoaxiológica, porque el conocimiento de la educación sirve para valorar como educativo el medio o contenido que se utiliza en el proceso educativo, ajustándolo a criterios de educación establecidos desde el conocimiento 
de la educación. Desde esta perspectiva se puede decir, por ejemplo, que, al ajustar el área de experiencia cultural utilizada en el proceso instructivo a criterios educativos, la construimos como ámbito de educación y nos ponemos en condiciones de educar $\mathrm{CON}$ el área de experiencia cultural correspondiente a nuestra materia escolar (Historia, literatura, artes, etcétera). La clave de esta perspectiva reside en defender y fundamentar que (Touriñán, 2018):

- Conocer, enseñar y educar son conceptos distintos con significado propio.

- Transformamos información en conocimiento y este en educación, por medio del conocimiento de la educación.

En perspectiva mesoaxiológica, la posibilidad de acción pedagógica es definida: conocer, enseñar y educar son conceptos distintos; la lógica de saber no es la lógica de hacer saber a otro y hay enseñanzas que no educan, por tanto, enseñar no es educar Además de enseñar, hay que educar, transformando información en conocimiento y éste, a su vez, en educación, ajustándolo al significado de educar. Y hay, además, un riesgo constante: el conocimiento de la educación fundamenta la decisión pedagógica, que es técnica y de perspectiva mesoaxiológica, pero no es suficiente para garantizar que nadie saltará el limite pedagógico, politizando la educación, adoctrinando, manipulando o eligiendo en lugar del educando su sentido de acción y su modo de vida.

Afirmar que estudiar es actividad propedéutica y por tanto un medio útil para educar, investigar, intervenir y dominar las materias escolares, entre otras posibilidades instrumentales de estudiar, parece una obviedad, pero resulta curioso comprobar que el concepto «estudiar» no aparece en los diccionarios de uso frecuente en investigación pedagógica, al menos con la consideración de entrada principal o artículo. Lo normal, cuando aparece, es reorientar la entrada hacia el término «estudiante», o despacharlo simplemente con la idea de que estudiar es el trabajo propio del estudiante en el ámbito escolar para conseguir el aprendizaje de materias en un determinado currículum. A su vez, en el caso del concepto de estudiante, suelen remitirnos a la consulta de las voces «alumno» o «juventud», induciendo a la confusión de significados entre enseñar, aprender, estudiar y educar. Los tratamientos más divulgados del significado de estudiar se vinculan a otro término que sí es merecedor de entrada especifica en diccionarios: "técnicas de estudio».

El valor pedagógico de estudiar no está, en perspectiva mesoaxiológica, en dominar técnicas de estudio y alcanzar con ellas una finalidad sea educativa o no. En este caso, estudiar es una actividad instrumental especificada que se usa para educar, o para preparar un porvenir profesional o para vencer a un contrincante o para ganar un premio, etc. Eso es importante y ya está fundamentado en la literatura especializada. En perspectiva mesoaxiológica, hay que dar un paso más; lo fundamental es responder a la pregunta de por qué la actividad de estudiar, en tanto que actividad, educa. No es valorar el medio, porque cumple un fin (fin 
educativo), sino si la actividad propia del medio, si el medio en sí, en tanto que actividad, es educativo.

Yo he dedicado, desde 1986, diversos trabajos al concepto de estudiar y estudiante, analizando, en unos casos, su significado y, en otros lo que implica la mentalidad de estudiar frente a la de investigar y a la de intervenir. Y conviene resaltar que la ausencia de estudios específicos del valor educativo acerca del término 'estudiar' se debe, no solo a la no existencia tácita o explícita de un acuerdo unánime acerca de su significado, sino también a la generalizada convicción de que estudiar es solo es un medio para un fin deseable (educar) y que educar es lo que merece la atención pedagógica (Touriñán, 1986; Touriñán, 2016, cap. 10; Touriñán 2017, cap. 1; Touriñán y Sáez, 2015, cap. 6). Un indicio de la verdad de la afirmación anterior es, por una parte, la comprobación de que, siendo comúnmente aceptado que estudiante es la persona que estudia, no todos deducen de ello las mismas consecuencias (algunos defenderán, con razón, que no toda persona que estudia es estudiante y que hay estudiantes que no estudian) y, por otra, la incuestionable verdad de que, para unos, estudiar es un medio de crear cultura y, para otros, una forma de alcanzar el dominio de la cultura creada, o una forma de preparar un porvenir profesional, o un medio para aprobar un examen (Colom y Touriñán, 2008; Elam, 1973; Guiton, 2019; Mosterín, 2009; Ortega y Gasset, 1968; Pieper, 2018).

Desde esta perspectiva, puede afirmarse que hoy no se duda de la importancia del tema "estudiar», ni se cuestiona tampoco su actualidad que nace del propio carácter de la sociedad actual, como sociedad escolarizada, de aprendizaje, educativa y del conocimiento. Es más, se es consciente de la trascendencia del estudiar, porque estudiar es una condición necesaria como actividad propedéutica: hay que asimilar el acervo cultural de las generaciones anteriores y educarse, y para ello hay que estudiar. Y en esa misma línea de pensamiento están los trabajos que identifican estudiar con dominar técnicas de estudio (Carbonell, 1988; 1989; Hernández y García, 1991; Martín, 2007; Robinson, 1970; Staton, 1996; Sánchez, 1991; Tierno, 2003; Vera y Esteve, 2001).

Cada vez es más obvio que enseñar a estudiar es una tarea especializada que incumbe de manera primordial a cada profesor en su materia, sin embargo, lo que yo pongo en duda es la posibilidad pedagógica de crear secuencias racionales de acción para lograr educar con la actividad de estudiar, sin reparar en la condición propia de la actividad: por el hecho de estudiar nos formamos y nos educamos; la actividad en sí, de estudiar, educa.

En España, el estudiar como actividad en sí y como análisis conceptual que merece la pena ser hecho fue abordado por vez primera en 1933 por el filósofo Ortega y Gasset bajo el título "Sobre el estudiar y el estudiante» (Ortega, 1968) La tesis inicial de Ortega es que no se duda de la importancia propedéutica del término 'estudiar', y que estudiar es una condición necesaria del mundo actual y que conocer la actividad de estudiar mejora la posibilidad pedagógica de crear secuencias 
racionales de acción que benefician el aprendizaje de los estudiantes. Pero, para Ortega, estudiar como actividad es una falsedad, porque no es necesidad intrínseca, auténtica necesidad psicológica, nacida de dentro del sujeto y está conectada con el dominio de las materias escolares y no con el saber:

El hecho es que el estudiante tipo es un hombre que no siente directa necesidad de la ciencia, preocupación por ella y, sin embargo, se ve forzado a ocuparse de ella. Esto significa ya la falsedad general del estudiar. Pero luego viene la concreción, casi perversa, por lo minuciosa, [...] porque no se obliga al estudiante a estudiar en general, sino [...] disciplinas singulares [...]. ¿Quién va a pretender que el joven sienta efectiva necesidad, en un cierto año de su vida, por tal ciencia que a los hombres antecesores les vino en gana inventar? (1968, p. 121)

Yo hice un análisis pormenorizado de la tesis de la falsedad del estudiar en mi artículo "Delimitación pedagógica de estudiar y estudiante» (Touriñán, 1986) y puede mantenerse con fundamento desde ese trabajo que la tesis de la constitutiva falsedad del estudiar es errónea, porque (Touriñán, 2017, pp. 44-51):

a) Las necesidades psicológicas, con independencia de su origen, son necesidades porque nos exigen algo sin marcarnos de forma incondicionalmente eficaz el modo en que han de ser satisfechas. En tanto que exigen algo, las sentimos como tales; y en la medida que somos conscientes de ellas, de sus síntomas y de los efectos que se producirían según se satisficieran o no, decidiremos nuestra acción. Precisamente por eso es tan auténtica nuestra necesidad de sanar, como nuestra necesidad de estudiar o como nuestra necesidad de saber, si bien no tienen la misma procedencia ni condición.

b) Estudiar no es una necesidad en el mismo sentido que saber o resolver un problema. Saber o resolver un problema es una necesidad en sentido psicológico, lo mismo que restablecer la salud o curarse, y en todos esos casos la necesidad psicológica se convierte en finalidad en el marco de la acción humana, porque hay relación valor-obligación. El recurso que utilizamos para poder satisfacer la necesidad es el libro, las disciplinas, en un caso, y la medicina recetada, en otro, y ambos son ordinariamente recursos específicamente apropiados para esa necesidad. Lo que hay que hacer para satisfacer la necesidad es, en un caso, estudiar, y en el otro, inyectarse la medicina, y en ambos casos constituyen una necesidad lógica o condición necesaria.

c) Son dos cosas distintas afirmar que el estudio es siempre una falsedad y afirmar que el estudio puede convertirse en una falsedad. Al incitar a una persona a estudiar no la incitamos a una falsedad, antes bien, la incitamos a que asuma lo que tiene que hacer (que ejecute una función específica, vinculada de alguna manera a la finalidad y al recurso utilizado) para 
satisfacer su necesidad de saber que es auténtica. Si esto no fuera así, tendríamos que decir que, cuando incitamos a una persona a ponerse una inyección (para curar la enfermedad), la estamos incitando a una falsedad y no a hacer lo que tiene que hacer para satisfacer su necesidad de salud que es auténtica Cuando el profesor no logra enseñar la relación entre estudiar y saber y disciplina a estudiar, o no tiene la confianza de los alumnos, el estudiar se capta como una condición necesariamente impuesta para un fin que no se entiende (dominar las disciplinas, alejadas de su conexión con el saber). En tales casos el alumno o se somete o se subleva. Por la sumisión se abre la vía a la posibilidad de falsear el estudio. Pero eso no significa que la actividad de estudiar sea una falsedad, sino que, en determinados casos, al estudiar somos actores de una actividad, pero no nos sentimos autores de esa actividad y ni nos comprometemos con ella, ni nos responsabilizamos de ella; convertimos el estudio en una falsedad.

La definición de estudiar puede verificarse de una doble manera: como definición nominal o como definición real, según se atienda, respectivamente, a la palabra o nombre con que designamos a una cosa, o a los rasgos y caracteres peculiares de la cosa nombrada. La definición nominal ofrece, pues, la significación de una palabra; en tanto que la definición real es expresiva de los caracteres distintivos y singulares de la cosa.

Se tiene la firme convicción de que estudiar es una ocupación habitual que supone la ejecución de una determinada actividad a través de la cual se aprenden cosas y que, como tal actividad, es susceptible de instrucción y entrenamiento. Por etimología y sinonimia, propias de la definición nominal, se sabe que estudiar (Touriñán, 2017):

- Por el uso común que se hace del término, es tratamiento especial de la información escrita, cualquiera que sea su soporte tecnológico

- Por la actividad que se realiza de manera significada, estudiar no es investigar, ni preparar exámenes, sino una actividad intencional de rendimiento observable, con finalidad propia

- Por la función simbólica y significación que se confiere a la actividad, estudiar no es profesionalizar, sino dominar la información dada; lograr saber.

Desde la perspectiva de la definición real, los rasgos constitutivos de estudiar se concretan en actividad dirigida a disponer y organizar una información escrita (cualquiera que sea su soporte tecnológico) para lograr su dominio (saber), con independencia de que pueda ser utilizada o no posteriormente para otra finalidad externa como pueden ser educar, robar, profesionalizar, resolver problemas, ganar un concurso, etcétera. Y si esto es así, puede decirse que la actividad de estudiar es 
"educativa», porque se vincula como medio a una finalidad educativa: estudio para realizar una finalidad educativa que se vincula al estudio (por ejemplo: estudio un contenido axiológicamente valioso en su ámbito, es decir, en Biología, estudio para entender la célula y su importancia en la vida).

Así queda fijado el valor educativo de la actividad de estudiar como actividad propedéutica (orientada a un fin distinto de la propia actividad). Pero, en perspectiva mesoaxiológica, no es lo mismo valorar la actividad de estudiar, porque es un medio para educar, que valorar la actividad de estudiar, porque la actividad en sí educa; es decir, no significa lo mismo para la Pedagogía decir que estudiamos para educarnos (para lograr finalidades educativas), que decir que, al estudiar, nos educamos. Si esa diferencia se significa, estudiar no solo tiene valor propedéutico, sino valor educativo en sí, porque la propia actividad de estudiar, al ser ejecutada, nos educa. En este caso, lo importante no es qué cosa estudio y cuál es la finalidad instrumental del estudio, sino que lo importante es la actividad misma de estudiar, porque me 'educo con' la actividad y no solo por la meta que persigo, usando esa actividad.

En perspectiva mesoaxiológica, además de considerar la actividad de estudiar como actividad propedéutica especificada para una meta vinculada empíricamente al medio 'estudiar', hay que considerarla como actividad en sí misma cuya realización nos educa, al ejecutar la actividad: es cierto que estudiar es un medio para un fin educativo, pero también es cierto que nos educamos con la actividad de estudiar y por tanto, al estudiar, nos educamos; la actividad en sí de estudiar, educa, al ejecutarla. A esta tarea dedicamos la argumentación en este trabajo, vinculando la actividad de estudiar a los rasgos propios de la actividad, al sentido pedagógico del principio de actividad y a la concordancia valores y sentimientos que se requiere en la ejecución de la acción de estudiar. Podemos estudiar para educarnos, para divertirnos, para robar mejor, para ayudar a otro, etcétera, es decir, podemos utilizar la actividad estudiar como medio para alcanzar la finalidad de educar o para otra finalidad distinta de educar en una relación medio-fin. Pero además de usar la actividad de estudiar para educar y reconocer el valor pedagógico de ese uso, es posible afirmar que la actividad de estudiar, como tal, se ajusta al significado real de educar, es decir se ajusta a los rasgos de significado que le son propios a educar y al ejecutar la acción de estudiar para dominar un contenido, se perfeccionan y desarrollan esos rasgos, con independencia de utilizar la actividad de estudiar para otras finalidades. 
JOSÉ MANUEL TOURIÑÁN LÓPEZ

ESTUDIAR ES ACTIVIDAD COMÚN EXTERNA Y SIEMPRE EDUCAMOS CON LA ACTIVIDAD. UNA APROXIMACIÓN DESDE LA PERSPECTIVA MESOAXIOLÓGICA

\section{EN PERSPECTIVA MESOAXIOLÓGICA, ESTUdIAR SE ACEPTA COMO ACTIVIDAD PROPEdéutica, PERo SU VAlOR PEDAgógico No HAY QUE REDUCirlo A ESO, HAY QUE BUSCARLO EN SU CONDICIÓN DE ACTIVIDAD EN Sí}

Hoy se asume la importancia propedéutica del término estudiar; la caracterización de nuestra sociedad como espacio de explosión escolar, como espacio de sociedad del saber y como espacio de sociedad educativa, así lo avalan; estudiar tiene valor propedéutico (Touriñán y Sáez, 2015, cap. 6):

1. El informe Faure, "Aprender a ser, formulado a principios de los años setenta del siglo XX, que puede ser considerado como el estudio de las constantes, problemáticas y estrategias a seguir para la educación del futuro, mantiene que, en la educación, en ese momento, existen tres fenómenos nuevos, históricamente hablando (Faure, 1973):

- La extensión de la educación considerada a escala planetaria tiende a preceder al nivel del desarrollo económico por primera vez en la historia de la humanidad.

- La educación se emplea conscientemente en preparar a los hombres para tipos de sociedades que todavía no existen.

- Aparecen contradicciones entre los productos de la educación y las necesidades sociales de manera que diversas sociedades comienzan a rechazar un gran número de productos ofrecidos por la educación institucionalizada.

La «explosión escolar», lema que preside las reflexiones del Informe Faure, significa que la extensión de la educación a muy diversos sectores de la población, hace que todos en cualquier momento de nuestra vida, todos tenemos que estudiar e incluso podamos asumir la condición de estudiante que cursa estudios reglados; pero hace, también, que el propio concepto de estudiante se desdibuje en su perfil delimitado al introducirse en la categoría de estudiante al adulto, con lo cual, la sinonimia joven-estudiante se relativiza y con ello se relativiza, además, la validez general de los trabajos que identifican la preocupación estudiantil con la preocupación juvenil (Elvin, 1973; Elzo et al., 2003; Touriñán, 2009).

2. La caracterización de nuestra sociedad como una sociedad del saber, es decir, como una sociedad en la que existe un ritmo acelerado de cambio en los conocimientos y un volumen de información incapaz de ser asimilado sin tecnología adecuada (Bell, 1976; Botkin, 1976; Husén, 1978 y 1985; Neira, 2011; Toffler, 1976 y 1980; Touriñán, 1999, 2004;2005), hace más patente la necesidad de examinar mucho más concienzudamente la materia de los temas que ofrece la escuela a fin de determinar qué es lo que debe o no debe estudiarse. Se evidencia la importancia del estudio porque todos, en mayor o menor medida, tenemos que ejercer esa 
actividad; unos, por razón de profesión, durante toda la vida; otros, en diversos momentos de la existencia, para no quedar desbordados por la complejidad de los problemas que nos plantea la propia existencia. Se evidencia la importancia del estudio, pero se evidencia, además, la necesidad de caracterizar de forma perfectamente diferenciada qué es esa actividad que consiste en estudiar porque, como dice Nieto García, en una 'sociedad del conocimiento' hemos de estar preparados para aprender unas ideas y técnicas que luego hay que olvidar para recoger otras nuevas, cuando se hacen obsoletas, y olvidar es más difícil que aprender (Nieto García, 1980, p. 152; SI(e)TE, 2016; 2019).

Nuestra sociedad es, en efecto, una sociedad del conocimiento en la que la información desborda los canales tradicionales de transmisión y exige educación de calidad: no sólo se demandan nuevos modos de comunicación, sino nuevos modos de enfrentarse a la información que permitan, con criterio adecuado, estar al día en nuestro ámbito. El problema es, por un lado, formar el juicio y el criterio, es decir, no sólo adquirir información, sino saber desprenderse o dar un tratamiento adecuado a la que queda obsoleta, desde la comprensión del problema y, por otro lado, asumir que el conocimiento se ha convertido en cuestión de Estado y motor del desarrollo social, cultural, y económico productivo y crítico, de manera que la innovación, el emprendimiento y la transferencia de conocimiento se han convertido en misión prioritaria en el sistema conocimiento-educación-innovación-desarrollo (Colom y Touriñán, 2009; Husén, 1985; SI(e)TE, 2018; Touriñán, 2013, 2019a).

3. Nuestra sociedad es, además, una «sociedad educativa». Este lema, que es el título en castellano de un libro de T. Husén, pone de manifiesto los aspectos más importantes de la necesidad social de calidad de educación que han sido recogidos por diversos autores. Por una parte, advierten que educación de calidad y escolarización no se identifican de forma absoluta y, por consiguiente, la escuela tiene que adecuarse a las demandas actuales. Por otra parte, hacen especial hincapié en el reto de la virtualidad educativa de los sistemas no formales, informales y electrónicos, para la calidad de la educación (Botkin, 1979; Delors, 1996; Hallak, 2003; Esteve, 2010; Husén, 1978; Morín, 2000; 2002; Neira, 2011; Touriñán, 2016, cap. 9; Touriñán y Soto, 2005).

El reto exige asumir que los recursos virtuales se utilizan para hacer intervención pedagógica. El objetivo final del aula virtual no es sustituir al profesor o la orientación del aprendizaje, sino facilitar otro entorno que amplía las posibilidades de intervención, pero no conculca las condiciones básicas del proceso de intervención que siempre tiene agentes, intencionalidad educativa e intervención pedagógica para que se consiga modificar pedagógicamente con los determinantes externos (conductas del tutor y profesor) los determinantes internos de la conducta del alumno (Touriñán, 2014). Las mediaciones tecnológicas y los entornos virtuales de aprendizaje se convierten hoy en un recurso fundamental de educación y 
la actividad de estudiar se integra en la nueva situación, porque el aprendizaje es siempre aprendizaje situado (Díaz Barriga, 2006; Touriñán y Longueira, 2018).

Pero dicho esto, también tenemos que decir que en Pedagogía hemos llegado ya a la comprensión de que conocer, enseñar y educar son tareas diferentes. Además de enseñar, hay que educar, transformando información en conocimiento y éste, a su vez, en educación, ajustándolo al significado de educar. Desde el punto de vista del conocimiento de la educación, al que enseña se le requiere un determinado nivel de aptitudes vinculadas al conocimiento aquello que será objeto de la enseñanza (dominar la actividad de estudiar), pero de ahí no se sigue que enseñar esa actividad sea conocer esa actividad y que educar sea simplemente enseñar la actividad. Es innegable, dado el actual desarrollo del conocimiento de la educación, que todos los profesores no requieren el mismo nivel de pericia en el área cultural de experiencia que enseñan (sea estudiar u otra), aunque todos deben saber enseñar; ese nivel de pericia exigible en la actividad a enseñar varía según cuál sea la etapa del sistema educativo en la que se imparta la docencia Y es innegable, también, que todos los profesores no deben tener el mismo conocimiento pedagógico, porque ese conocimiento varía y se ajusta, dependiendo de las necesidades educativas a resolver que son específicas del nivel concreto del sistema educativo en el que se trabaje.

Atendiendo a lo anterior, es obvio que se requieren competencias distintas para educar, para enseñar y para conocer la actividad de estudiar. Al profesional de la educación le corresponde, con fundamento de elección técnica, decidir: si el educando puede alcanzar los objetivos instructivos (dominar una técnica de estudio); si los objetivos son coherentes con la representación conceptual de la intervención educativa; si el contenido utilizado para enseñar tiene fundamento teórico, tecnológico y práxico, según el caso, en el conocimiento de la educación para ser utilizados como instrumento de la educación; qué nivel de contenidos es adecuado en un caso concreto, cual es el método de enseñanza adecuado y qué destrezas, hábitos y actitudes, conocimientos y competencias educativas se pueden desarrollar con la enseñanza de esa actividad. Es decir, el profesional de la educación domina los conocimientos teóricos, tecnológicos y práxicos de la actividad que va a enseñar, al nivel suficiente para enseñarlos; pero, como profesional de la educación, domina el conocimiento de la educación que le permite justificar y explicar la conversión de esos conocimientos de la actividad en objetivo o instrumento de la intervención pedagógica.

Conocer una actividad no es lo mismo que enseñar esa actividad, porque las competencias que se requieren en cada caso son distintas y enseñar una actividad no es lo mismo que educar con esa actividad, porque podemos afirmar que hay enseñanzas que no educan, con fundamento en el significado propio de esos términos. Y, así las cosas, conocer y saber estudiar, enseñar a estudiar y educar CON el estudio, por poner un ejemplo de área de actividad, no significan lo mismo. 

UNA APROXIMACIÓN DESDE LA PERSPECTIVA MESOAXIOLÓGICA

Educar, es básicamente desarrollar en cada persona los valores de acuerdo al significado del concepto 'educación' y utilizar las actividades que realizamos para generar en los educandos destrezas, hábitos, actitudes, conocimientos y competencias que los capacitan para decidir y realizar su proyecto de vida personal y construirse a sí mismos, sin perjuicio de la posibilidad de abordar, además, el área de actividad como manifestación cultural que es cognoscible, enseñable, investigable y realizable (convertirse en especialista y experto en técnicas de estudio). Educar CON el estudio no es lo mismo que saber estudiar, que enseñar a estudiar, o que mejorar nuestra capacidad cognitiva desde el estudio o mejorar nuestras técnicas de estudio.

Hay que asumir sin prejuicios que la Pedagogía es conocimiento de la educación y este se obtiene de diversas formas, pero, en última instancia, ese conocimiento, por principio de significación, sólo es válido si sirve para educar; es decir, para transformar la información en conocimiento y este en educación, ajustándose al significado de educar. Por una parte, hay que saber en el sentido más amplio del término (sé qué, sé cómo y sé hacer); por otra parte, hay que enseñar (que implica otro tipo de saber distinto al de conocer la actividad que enseño); y, por si eso fuera poco, además, hay que educar, que implica, no sólo saber y enseñar, sino también dominar el carácter y sentido propios del significado de 'educación', para aplicarlo, en cada caso concreto de intervención y bajo criterio pedagógico de diseño educativo, a cada actividad concreta con la que educamos (Touriñán y Longueira, 2018). Cuando abordamos una actividad o una experiencia o un contenido con mentalidad pedagógica específica y mirada pedagógica especializada, la representación mental que hacemos de la acción de educar (mentalidad) y la visión crítica que tenemos de nuestro método y de nuestros actos pedagógicos (mirada) nos permiten distinguir entre «saber una actividad», «enseñar esa actividad» $\mathrm{y}$ «educar con la actividad", entendida esta como una actividad sistematizada que forma parte del currículo junto con otras y se ha convertido en ámbito de educación desde la Pedagogía (Touriñán, 2017).

Por principio de significado, conocer una actividad no es enseñarla, porque el conocimiento puede estar separado de la acción (la lógica de conocer y saber, no es la lógica de hacer saber, que implica siempre acción y no solo conocimiento) y, a su vez, enseñar la actividad no es educar con ella, porque podemos afirmar que hay enseñanzas que no educan y porque, con fundamento en el significado propio de esos términos, diseño instructivo y diseño educativo no significan lo mismo (la lógica de enseñar no es la lógica de educar, que debe ajustarse al criterio de significado que es propio del término 'educar').

En perspectiva mesoaxiológica, puede afirmarse que la diferencia específica de la función de educar no se la otorga la cantidad y calidad de la actividad que utilizamos como medio, sino el ajuste efectivo del medio, como resultado de su valoración educativa, al significado de educar desde principios de educación y de intervención pedagógica (Touriñán, 2018). 
En perspectiva mesoaxiológica, estudiar, en tanto que actividad propedéutica, que se usa para lograr resultados o finalidades distintas de la que se identifica conceptualmente como la lógicamente propia de la actividad, se define como una actividad instrumental especificada. La finalidad propia, vinculada conceptualmente de manera lógica con el estudio es el dominio del tema que se estudia o el logro de saber aquello que se estudia. Pero además la actividad, cuando se domina, permite ser utilizada como actividad instrumental especificada para otra finalidad vinculada empíricamente con el medio (actividad de estudiar): estudio para educarme, desarrollando sentido crítico, pero también puedo estudiar para, informarme, robar mejor, ganar dinero, engañar a un colega, profesionalizarme, aprobar un examen, ganar un concurso, etcétera; todas ellas metas vinculadas empíricamente con la tarea de estudiar). Esto es lo que Claxton denomina el "plus del aprendiz»: para dominar una actividad tenemos que aprender a hacerla, invirtiendo tiempo y esfuerzo, ahora bien, una vez que se ha hecho esa inversión, la actividad aprendida se convierte en recurso que posibilita diferentes tipos de exploración y de uso y puede aportar un rendimiento cada vez mayor. Una nueva área de aprendizaje se abre por un cambio de herramienta (actividad aprendida), y una clase diferente de competencia cobra vida; la competencia hace un uso creativo de la herramienta, igual que la herramienta conforma el desarrollo de la competencia (Claxton, 2001, p. 248).

Esto nos confirma que estudiar tiene un fin propio vinculado a esa actividad de manera conceptual y lógica (el fin propio de estudiar es dominar-saber aquello que se estudia: una información, un contenido o la propia técnica de estudio), y que, además es un medio instrumental de otras finalidades especificadas y distintas a la finalidad que es conceptualmente identificativa y propia de la actividad de estudiar; son finalidades vinculadas a la actividad de estudiar de manera empírica o experiencial (estudiar se convierte en actividad instrumental especificada, porque puedo estudiar para robar, para hacer amigos, para ayudar a otro, para educarme, etcétera). Identificar y discernir estos valores propedéuticos de la actividad de estudiar, sea propedéutica para educar o propedéutica para otra finalidad, es necesario para poder argumentar sobre el uso de la actividad de estudiar. Ahora bien, eso no anula la importancia y pertinencia de indagar sobre la actividad de estudiar en sí misma y resaltar el valor pedagógico de la actividad en sí. Tiene sentido preguntarse acerca de la actividad de estudiar, en sí misma y defender que estudiar, como actividad en sí misma, educa y es objeto de intervención educativa y de intervención pedagógica.

\section{ESTUDIAR ES OBJETO DE INTERVENCIÓN PEDAGÓGICA Y DE INTERVENCIÓN EDUCATIVA COMO ACTIVIDAD PROPEDÉUTICA Y COMO ACTIVIDAD EN Sí}

La intervención educativa es la acción intencional para la realización y el logro del significado de educar y de los fines de la educación, es una relación mediosfines que debe ajustarse al significado de educar (Touriñán, 1997). La intervención educativa tiene carácter teleológico: existe un sujeto agente (educando-educador) 

UNA APROXIMACIÓN DESDE LA PERSPECTIVA MESOAXIOLÓGICA

existe el lenguaje propositivo (se realiza una acción para lograr algo), se actúa en orden a lograr un acontecimiento futuro (la meta) y los acontecimientos se vinculan intencionalmente. La intervención educativa se realiza mediante procesos de autoeducación y heteroeducación, ya sean estos formales, no formales o informales. La intervención educativa exige respetar la condición de agente en el educando. La acción (cambio de estado que un sujeto hace que acaezca) del educador debe dar lugar a una acción del educando (que no tiene que ser intencionalmente educativa) y no sólo a un acontecimiento (cambios de estado que acaecen a un sujeto en una ocasión), tal como corresponde al análisis de procesos formales, no formales e informales de intervención (Touriñán, 1996).

A su vez, la intervención pedagógica es la acción intencional que desarrollamos en la tarea educativa en orden a realizar, con, por y para el educando, los fines y medios que se justifican con fundamento en el conocimiento verdadero de la educación (Touriñán, 1987). La intencionalidad reside en la conducta; y ver una conducta como intencional, es comprenderla como un conjunto de actuaciones implicadas, por lo que el propio agente cree, en la consecución de algo (Von Wright, 1979). El proceso de intervención pedagógica podría esquematizarse del siguiente modo: "A" (agente educador) hace "X" (lo que el conocimiento de la educación explica y justifica) para conseguir el resultado «R» (que «B» - agente educando- efectúe las conductas "Y» —explicitadas en la intervención pedagógica de "A»— y alcance el objetivo «Z» —destreza, hábito, actitud o conocimiento educativo (Touriñán, 2016).

Intervención educativa e intervención pedagógica no se identifican necesariamente, aunque en toda intervención educativa haya un componente de intervención pedagógica. Esto es así, porque ninguna acción educativa requiere más nivel de competencia técnica (pedagógica) que la necesaria para hacer efectiva la meta de la acción; hay acciones que requieren bajo nivel de competencia técnica y son efectivas; hay acciones cuyo nivel de competencia técnica se ha divulgado y forman parte del acervo común de una cultura; es posible adquirir competencia técnica desde la propia práctica. Un padre educa, un sujeto puede autoeducarse, existen procesos de educación informal; en todos estos procesos, se alcanzan resultados educativos, pero es muy probable que la competencia técnica no tenga en estos casos el nivel necesario para controlar el proceso o decidir acerca de mejores formas de intervención, que es consubstancial a la intervención pedagógica (Touriñán, 2014).

La diferencia entre intervención educativa e intervención pedagógica es la misma que existe, salvando las diferencias de significado, entre las expresiones "sé hacer algo" y "sé por qué haciendo de ese modo, se logra ese algo y sé qué otros modos hay de lograrlo y sé qué habría que hacer para reconducir el proceso adecuadamente». En todos esos casos hay conocimiento de la educación, pero su capacidad de resolución de problemas es distinta. La diferencia entre intervención educativa e intervención pedagógica es una elaboración conceptual derivada del avance del conocimiento de la educación. 
JOSÉ MANUEL TOURIÑÁN LÓPEZ

ESTUDIAR ES ACTIVIDAD COMÚN EXTERNA Y SIEMPRE EDUCAMOS CON LA ACTIVIDAD. UNA APROXIMACIÓN DESDE LA PERSPECTIVA MESOAXIOLÓGICA

En definitiva, en la intervención pedagógica, de lo que se trata, es de generar hechos y decisiones pedagógicas. La condición de experto viene dada por estar en posesión de competencias desarrolladas con el conocimiento teórico, tecnológico y práctico de la educación, el dominio de la complejidad estructural de la toma de decisiones pedagógicas y el entrenamiento en la intervención como especialista de la educación (Touriñán, 2017).

Desde la Pedagogía, no hay fundamento para suponer que el desarrollo responde a una embriología regulada hereditariamente, de tal manera que la acción del educador se limitaría a presentar los estímulos adecuados a cada etapa. Ni hay fundamento para suponer que el desarrollo depende únicamente de la experiencia individual y las influencias del medio físico y social, de tal manera que el profesor puede acelerar el desarrollo hasta el punto de quemar etapas e identificar lo más rápidamente al niño con el adulto (Piaget, 1980, p. 192 y ss.).

En ambos casos, es obvio que la condición del educando sería la de paciente. Y la pasividad es contraria al principio de actividad. El educando, en realidad, no actuaría; se viviría como puro espectador de los sucesos que en él ocurren; en ambos casos, la educación sería un cambio de estado que tiene lugar o acaece en el educando; sería, por supuesto, acción del educador, pero no del educando. Frente a la pasividad del educando, respecto de la preponderancia de la herencia o el ambiente, sigue siendo verdad que:

Jamás hay herencia sin ambiente. Toda herencia influye como lo hace porque el ambiente en que acontece es como es. Si cambia el ambiente, no de cualquier manera, sino de una determinada, se produce en igualdad de condiciones genéticas una determinada variación en el desarrollo [...]. Jamás hay ambiente sin herencia. Todo influjo ambiental produce el efecto que logra porque incide sobre un proceso genéticamente codificado [...]. Si cambia la dotación genética, no de cualquier manera, sino de una determinada, se produce en igualdad de condiciones ambientales, una determinada variación en el desarrollo $[\ldots / . .$.$] . El desarrollo no es el despliegue automático de un código genético$ dado, ni la modelación del ambiente sobre una dotación pasiva, sino el resultado de la utilización activa de las condiciones ambientales por un ser vivo genéticamente dotado [...]. Cada uno tendrá sus dotes y peculiaridades emotivas heredadas. Pero su personalidad y su vida no estriban principalmente en ellas, sino en lo que con ellas se hace (Yela, 1978, pp. 6 y 23).

El desarrollo depende, no sólo de lo que el hombre tiene, sino de lo que hace con lo que tiene. El reflejo oculocefalógiro no explica la búsqueda del objeto, cuando ha salido del campo visual, si no entendemos la asimilación de lo real a las coordinaciones necesarias y generales de la acción y de la toma de consciencia. Llegar a la integración interpretativo-creadora y a la integración comprensivo-cognitiva exige asumir que la consciencia, el afloramiento y la comprensión se inician en la cuna, el bebé comienza a mantener un contacto 'cara a cara', los padres manifiestan estar en presencia de un 'ser humano real' y los padres descubren que se hallan ante un 
'ser humano real' que se comunica (Bruner, 2009 y 2010; Damasio, 2010; García Carrasco, 2007, 2012; Pinker, 2007, 2011; Touriñán, 2016).

El profesional de la educación actúa con intencionalidad pedagógica que es el conjunto de conductas implicadas con fundamento de elección técnica en la consecución de la meta educativa. Su acción opera como determinante externo de la conducta del agente educando, es decir, de lo que este va a hacer para que se produzca en él el resultado educativo. Pero, como en el educando, el estímulo externo (lo que el educador dice que, con fundamento de elección técnica, debe hacerse), es transformado, si no se le anula su condición de agente, en un evento mental sin consecuencias ejecutivas necesarias, hay que tener en cuenta el posible desarrollo de los determinantes internos de la conducta del educando. Cuando hablamos de la intención no hablamos de algo que quede detrás o fuera de la conducta. Para nosotros no es sólo un acto mental, ni una experiencia característica que lo acompañe. La intencionalidad se identifica externamente con la descripción de los actos realizados para alcanzar la meta.

La intencionalidad reside en la conducta; y ver una conducta como intencional es comprenderla como un conjunto de actuaciones implicadas, por lo que el propio agente cree, en la consecución de algo. La intencionalidad educativa se da en los procesos de autoeducación y en los procesos de heteroeducación. La intervención pedagógica es la acción intencional en orden a realizar los fines y medios que se justifican con fundamento en el conocimiento verdadero de educar, ya sea en proceso de autoeducación o de heteroeducación.

Los procesos de autoeducación son procesos en los que los cambios educativos que se producen en un sujeto son resultado de acciones que ese sujeto realiza sobre sí mismo a partir de procesos educativos formales, no formales e informales y a partir de cualquier tipo de influencia. Son procesos de autoeducación, porque el sujeto que recibe la educación, no sólo es el agente del cambio que en sí mismo se produce, sino también el que se propone a sí mismo el cambio educativo; es decir, es autoeducación, porque las enseñanzas educativas se las da uno a sí mismo, no están expresas en las influencias de otras personas: son cambios, desde nuestra propia experiencia y a partir de experiencias que otros nos comunican, porque nadie se perfecciona en absoluto aislamiento de los demás, pero son cambios en los que el educando es agente actor, porque hace y elige hacer lo que hace en una relación de medios-fines, y es agente autor del cambio, porque integra sus elecciones de medios y fines en proyectos decididos, además de elegir hacer, decide actuar y se responsabiliza de su decisión.

Los procesos de heteroeducación son procesos en los que los cambios educativos que se producen en un sujeto son resultado de acciones que ese sujeto realiza sobre si mismo por medio de procesos educativos formales, no formales e informales. Son procesos de heteroeducación, porque el sujeto que recibe la educación es agente del cambio que en sí mismo se produce, pero no es él solo agente de 
JOSÉ MANUEL TOURIÑÁN LÓPEZ

ESTUDIAR ES ACTIVIDAD COMÚN EXTERNA Y SIEMPRE EDUCAMOS CON LA ACTIVIDAD. UNA APROXIMACIÓN DESDE LA PERSPECTIVA MESOAXIOLÓGICA

la propuesta de ese cambio, porque las enseñanzas educativas en este caso no se las da uno a sí mismo, sino que es otro agente (el educador) el que por medio de su comunicación nos manifiesta de modo expreso las enseñanzas educativas: son cambios desde la propia experiencia del educando, pero por medio de las experiencias educativas que otros nos comunican; el educando es agente actor, pero no es autor de la propuesta de cambio.

El educando es, por tanto, agente de los cambios educativos que en sí mismo se producen. En unos casos es agente actor de los cambios que el educador le propone. En otros casos es agente autor de los cambios que realiza y ha deccidido. El significado de agente marca un rasgo de carácter en la educación que no puede soslayarse, so pena de renunciar a educar. Se piensa siempre en la relación educativa como una relación entre dos, pero lo cierto es que la relación educativa es, de manera inequívoca, relación de uno consigo mismo. En la relación educativa somos cada uno de nosotros agentes-actores que nos dejamos guiar y obedecemos a las personas que ejercen la condición de educadores. Realizamos un montón de operaciones guiados para educarnos. Pero, además, somos agentes-autores que nos guiamos a nosotros mismos en procesos de educación, decidiendo nuestras metas e integrando nuestros actos en nuestros proyectos. Por medio de la educación emprendemos la terea de ser actores y autores de nuestros proyectos, incluso si nuestro proyecto es actuar según nos digan los demás. En cada caso, como agentes, estamos abocados, por la educación, a emprender la tarea de ser autores y actores de nuestros propios proyectos (Touriñán, 2015; SI(e)TE, 2012).

En los casos de heteroeducación, el educador es agente, porque a él le corresponde manifestar la intencionalidad educativa de forma exclusiva o no para lograr el resultado de la educación. Pero, a su vez, el educando es agente, porque no basta con que el educador disponga las cosas para que se produzca el cambio educativo en el educando; es necesario que éste se determine hacia la conducta que le propone aquel. El educando es agente de los cambios que propone el educador, porque, por alguna razón, hace lo que le proponen: adviértase que decimos hace lo que le proponen por alguna razón. Esto significa que el resultado educativo podría producirse en él sin el conocimiento o la intención de lograr el cambio educativo propuesto. Precisamente por eso podemos hablar incluso de educación en edades infantiles: el educando es agente porque hace lo que le proponen y el educador es, a su vez, agente, porque dispone las cosas para que el educando haga lo que tiene que hacer y se alcance la meta. Como dice Pinillos:

La forma en que inicialmente se libera el hombre de la tiranía del estímulo es la conversión de éste en un evento mental sin consecuencias ejecutivas necesarias [...]. Esa representación mental puede reanudar la causación interrumpida transitoriamente y dirigir la actividad cerebral hacia una respuesta efectiva quizás adaptativa, pero no directamente determinada por la estimulación (1978, p. 29) 
Así las cosas, el educando es agente de los cambios educativos que en sí mismo se producen, porque "por alguna razón" los quiere, si bien su intención no tiene por qué ser la de educarse en cada caso. Podemos no ser libres de encontrarnos en una determinada circunstancia; con frecuencia nos encontramos en una circunstancia sin que se nos pida nuestra libre aquiescencia. No somos libres de estar o no en ella, pero esto no supone sin más que no podamos determinarnos a actuar de un modo u otro. Lo propio de las circunstancias es que nos colocan forzosamente en situación de actuar, pero no son, cuando hablamos de educación, ni situaciones de grado de libertad nulo, ni situaciones de coacción intimidante, adoctrinamiento o manipulación

La explicación suficiente de las acciones humanas (y estudiar es una de ellas) debe darse en términos del modelo que hace referencia a la observación de reglas y propósitos y no sólo de causas. Esto es así por la simple razón de que, por una parte, la acción explicada en términos puramente físicos o fisiológicos pierde significado y, por otra, no hace innecesaria la intervención del agente (Cranach y Harré, 1982; Harré y Secord, 1979; Peters, 1958; Taylor, 1966).

Con intención de precisar el lenguaje conviene recordar que hablar de las causas como si fueran agentes que actúan, siendo responsables de sus efectos, es servirse de un lenguaje analógico o metafórico; el mismo lenguaje que se utiliza, cuando decimos que los agentes son causas. Las causas operan, producen su efecto sin hacer; basta con que estén presentes en las circunstancias propicias. No basta que los agentes estén presentes en el momento oportuno para producir el resultado, tienen que hacer algo:

Cuando decimos que la causa da lugar al efecto no queremos significar que la causa lo provoque haciendo algo. Gracias al hecho de tener lugar la causa logra el efecto [...]. Pero al hacer (agente) que la causa ocurra logramos o damos lugar a lo mismo que la causa produce por el hecho de tener lugar. Decir que nosotros causamos efectos no es asegurar que los agentes sean causas. Significa que hacemos cosas que, a título de causas, producen efectos (Von Wright, 1979, p. 93).

Las conexiones intencionales son vinculaciones de fenómenos de forma conceptual (Von Wright, 1980, pp. 189-191). Los fenómenos vinculados son conceptualmente dependientes porque exigen la referencia al juicio del agente acerca de por qué va a actuar como lo hace (Von Wright, 1980, p. 195).

Si yo digo "come dulces porque quiere tener caries» estoy estableciendo una vinculación explicativa entre las condiciones que afectan al acontecimiento a explicar. No es una conexión universal-deductiva, porque, ni es necesario comer dulces para que se produzcan caries, ni es suficiente comer dulces para producir ese efecto. Pero es una conexión probabilístico-inductiva, porque, si bien es verdad que caries y dulces no tienen que ir siempre unidas, también es verdad que los dulces son el factor insuficiente, pero necesario de un complejo condicional o campo de causación 
(condiciones específicas de dulces y dientes) que en sí mismo resulta innecesario (podría haberse dado otro complejo condicional, como por ejemplo, dientes y estado de desnutrición) aún cuando es suficiente para un determinado efecto (la aparición de caries). Y este complejo condicional de explicación INUS se aplica también al conjunto estudiar-libro-saber o al complejo estudiar-libro-educarse cuando se dice estudio porque quiero saber o estudio porque quiero educarme (Mackie, 1965, pp. 245, 249, 253, 255 y 257; Marc-Wogau, 1962, pp. 213-233; Dray, 1957, pp. 24-37, 39, 42, 43, 51 y 52; Wright, 1976; Von Wright, 1979, pp. 72-89).

Por el contrario, si yo digo "corre para coger el tren» $\mathrm{O}$ «estudio para saber» estoy explicando una relación entre dos fenómenos vinculados intencionalmente; son conceptualmente dependientes el uno del otro, porque la forma de relacionarlos reclama la referencia al juicio del agente acerca de por qué actuó como lo hizo. De nada vale la existencia de una vinculación nómica entre la velocidad que puedo desarrollar y la que está desarrollando el tren cuando inicia su recorrido, si no me he propuesto subir al tren. Y lo mismo ocurre, si no me he propuesto estudiar.

Cabe decir, por tanto, que, entre necesidad psicológica (saber-dominar un tema), recurso a utilizar (libro o texto escrito) y actividad que hay que ejecutar (estudiar) (necesidad lógica), se establece una vinculación conceptual que hace posible su explicación y comprensión como acontecimiento y acción intencional. Unas veces usamos la actividad unida a un recurso específico de la actividad para alcanzar la meta que está vinculada conceptualmente e intencionalmente con la actividad (estudiar-libro-saber). Otras veces usamos la actividad para otras metas, vinculadas con la actividad experiencialmente (ganar un premio, hacer amigos, ayudar, etc.

De acuerdo con estas reflexiones, puede decirse que la realización de una acción educativa no exige más nivel especializado de competencia técnica que el requerido para hacer efectiva la meta propuesta; esto quiere decir que existen muy diversas acciones educativas que no pueden ser resueltas sin competencia técnica. El estudio puede ser objeto de intervención educativa y de intervención pedagógica para lograr el dominio-saber del objeto de estudio (cualquier cosa o la propia técnica de estudio) y para utilizar el hábito de estudio como medio de conseguir otras metas, sean educativas o no. Pero, además, es exigencia de la perspectiva mesoaxiológica valorar el medio como educativo en sí mismo y perdemos credibilidad y capacidad de resolución de problemas, como técnicos competentes, si no orientamos la intervención en la actividad de estudiar a la posibilidad de educar que se deriva de la realización de la actividad: estudiar es actividad cuya ejecución, en sí misma, educa. Y eso puede probarse en tanto que estudiar es actividad común externa. 

UNA APROXIMACIÓN DESDE LA PERSPECTIVA MESOAXIOLÓGICA

\section{ESTUDIAR ES ACTIVIDAD COMÚN EXTERNA}

Sin pretensión de exhaustividad, hemos de decir que la acción es sólo un aspecto de la realidad. Entre otras cosas, en la realidad nos encontramos con estados, es decir, las propiedades, relaciones y situaciones en que una cosa o sistema está en un momento dado. Asimismo, nos encontramos con sucesos, acontecimientos o eventos que son cambios de estado en los que se da un estado inicial (que puede ser el final de otro acontecimiento) y un estado final (que puede ser el estado inicial de otro acontecimiento). Pero, además, nos encontramos con procesos que pueden ser definidos como la transición de un estado a otro (Cranach y Harré, 1982).

Ahora bien, los cambios de estado no acaecen solos. En ocasiones, se interviene en los cambios; es decir, hay un agente. Pues bien, todos los cambios producidos por intervención de un sujeto-agente se conocen como acciones. En virtud de esta precisión podemos hablar, por ejemplo, de un acontecimiento o suceso: la muerte de César, y de una acción: la de Bruto, que produjo la muerte a César (Dray, 1957).

Por consiguiente, cuando hablamos del cambio de estado que tiene lugar o acaece a un sujeto o cosa en una ocasión, hablamos de sucesos, eventos o acontecimientos, y, cuando hablamos del cambio de estado que un sujeto hace que tenga lugar o acaezca, hablamos de acciones.

Acto, acción, actividad, evento, estado, son palabras que se encuentran relacionadas. El Diccionario de la Lengua Española nos dice que actividad significa facultad de obrar y producir un efecto; conjunto de operaciones o tareas propias de una persona o entidad; estado de actuar, que se está en acción. Asimismo, nos dice que acto quiere decir el hecho concreto de la acción. Y con respecto a la palabra acción nos dice que, entre otras cosas, puede significar, ejercicio de una potencia, operación o impresión de cualquier agente en el paciente, ejercicio de la facultad de hacer alguna cosa.

De la simple consulta al Diccionario (DRAE, 2013), se desprende que los tres términos se relacionan con educación. En efecto, en toda obra u operación -y la educación es una obra - se da una facultad de obrar (actividad), el ejercicio de la potencia (acción) y el hecho concreto de hacer (acto). Dicho de otro modo: se desprende que los tres términos se relacionan con educación porque la educación es un acto con resultado específico; asimismo, la educación es actividad, un conjunto de operaciones o tareas específicas - no por otra cosa sino por esto hablamos de actividades educativas-; y, además, la educación es acción, es una determinada operación o impresión, una influencia y efecto específico de un agente (educador) sobre otro (educando).

Parecería, por tanto, que, de acuerdo con el lenguaje común, la razón de la preferencia por uno de los tres términos estribaría en la intención de resaltar uno u otro aspecto — acto concreto, actividades específicas o influencia que se ejerce- del 
desarrollo de la obra educativa. Ahora bien, frente a esa inferencia desde el lenguaje común hemos de reconocer que, cuando hablamos de la actividad, no queremos destacar el aspecto de las tareas específicas, ni el de resultados, ni el de función docente. Hablar de la actividad en educación supone reconocerla como principio, es decir, que en la actividad hay un carácter especial que debe estar presente del mismo modo en los resultados, en las tareas específicas y en la función del educador. Para la pedagogía activa, este carácter consiste en la necesidad de tener presente, tanto en las tareas educativas, como en los resultados, como en la función docente, que el educando no es solo un agente actor (que quiere los cambios propuestos en la acción del educador), sino también que es un agente autor (que decide y asume los cambios que en sí mismo se producen) (Ferrater, 1979, p. 88; Ferrater, 1980, p. 2702; Mosterín, 1978, p. 143; Von Wright, 1979, p. 54).

La importancia de la actividad es un hecho innegable en la pedagogía contemporánea. Si hubiera que resumir con una sola frase la pedagogía contemporánea, al menos en su ideal más claro y universalmente formulado, posiblemente tendríamos que considerar la nueva frontera educativa como la pedagogía de la actividad. Un somero repaso de las obras de Rousseau (1762), Montessori (1937), Dewey (1929, 1971 y 1998), Decroly (1929), Freinet (1978), Ferrer (1912), Piaget (1977) y Luzuriaga (1968), y los demás clásicos del activismo pedagógico y la Nueva educación, nos pone en situación de observar, desde una perspectiva diacrónica, las matizaciones que la palabra actividad ha ido manifestando en su significación educativa (Carbonell et al., 2000; Château, 1956; Marín Ibáñez, 1973, p. 94; Mialaret, 1979; Palacios, 1979; Piaget e Inhelder, 1972; Trilla, 2001).

En educación realizamos muchas acciones con el objeto de influir en el educando y lograr el resultado educativo. Son siempre acciones mediadas de un sujeto con otro o de un sujeto consigo mismo. Y todas esas acciones, que tienen que respetar la condición de agente del educando, buscan provocar la actividad del educando. En su uso más común, 'actividad' se entiende como estado de actividad, es actividadestado: la actividad es el estado en que se encuentra cualquier persona animal o cosa que se mueve, trabaja o ejecuta una acción en el momento en que lo está haciendo (decimos: este niño está pensando). Este uso hace referencia también a la capacidad que tenemos de acción en esa actividad y por eso decimos este niño ha perdido actividad (ahora piensa menos, ha dado un bajón). Por ser el uso más común del término 'actividad' como estado y capacidad, lo denominamos actividad común y se da en todas las personas porque en todas las personas hay actividad como estado y como capacidad de hacer (Touriñán, 1981, 2014).

Respecto de la actividad común, hemos de decir que la investigación actual distingue entre acciones ejecutadas para obtener un resultado y acciones cuyo resultado es la propia acción. Así, por ejemplo, la acción de resolver un problema tiene por resultado algo «externo» a la acción: obtener una solución (estudiar tiene 
como resultado dominar un tema;). En todos estos casos, no se puede ejecutar la acción de resolver el problema y tenerlo resuelto. Sin embargo, no puedo sentir sin estar sintiendo, pensar sin estar pensando, proyectar sin estar proyectando, etc. Las primeras son actividades externas y las segundas son actividades internas. Nosotros, desde ahora, hablaremos respecto de la educación, de actividad común (actividad estado y capacidad) interna (resultado es la propia acción: pensar, sentir, querer, operar, proyectar y crear) y externa (actividad estado y capacidad, cuyo resultado es externo a la propia acción, pero vinculado conceptualmente a la actividad en sí: tengo capacidad lúdica, tengo capacidad de estudiar, tengo capacidad de trabajar, de intervenir, de indagar-explorar y tengo capacidad de relacionar).

Desde la perspectiva de la actividad común interna podemos hacer una taxonomía de las actividades tomando como referente el agente educando. Todos convenimos en que, cuando nos educamos, sea auto o heteroeducación, nuestra condición humana nos permite realizar las siguientes actividades comunes internas: pensar, sentir afectivamente (tener sentimientos), querer objetos o sujetos de cualquier condición, operar (elegir-hacer cosas procesando medios y fines), proyectar (decidir-actuar sobre la realidad interna y externa orientándose) y crear (construir algo desde algo, no desde la nada, simbolizando la notación de signos: darse cuenta de algo — notar - y darle significado — significar-, construyendo símbolos de nuestra cultura). Nadie se educa sin estar pensando, sintiendo, queriendo, etc. Educarse es mejorar siempre esa actividad común interna y saber usarla para actividades especificadas instrumentales que nos hacen ser cada vez más capaces de decidir y realizar nuestros proyectos.

También convenimos en que, cuando nos educamos, nuestra condición humana nos permite realizar las siguientes actividades comunes externas: juego, trabajo, estudio, intervención, investigación-indagación-exploración y relación (de amigo, familiar, de pareja, social, etc.). Son actividades comunes (estado y capacidad), porque tengo capacidad para el estudio, el juego el trabajo, la exploración, la intervención y la relación. Y son actividades comunes externas, porque tienen necesariamente un resultado a obtener, que es externo a la actividad en sí, pero que está vinculado conceptualmente como meta a la actividad y la caracteriza como rasgo identitario. De ahí que digamos que estudiar es disponer y organizar información escrita "para" su dominio (dominar o saber el tema de estudio); el dominio-saber del tema de estudio es el resultado externo de la actividad y ese resultado es la finalidad que identifica el estudio, con independencia de que yo pueda utilizar el estudio para hacer un amigo, para ayudar altruistamente a otro, para robar mejor, etcétera, que son usos de la actividad como especificaciones instrumentales de ella.

Como actividad común externa, estudiar tiene un fin propio vinculado a esa actividad de manera conceptual y lógica (el fin propio de estudiar es dominarsaber aquello que se estudia: una información, un contenido o la propia técnica de estudio). Pero, además, como actividad común externa, estudiar puede convertirse 
JOSÉ MANUEL TOURIÑÁN LÓPEZ

ESTUDIAR ES ACTIVIDAD COMÚN EXTERNA Y SIEMPRE EDUCAMOS CON LA ACTIVIDAD. UNA APROXIMACIÓN DESDE LA PERSPECTIVA MESOAXIOLÓGICA

en actividad instrumental especificada para otras finalidades, son finalidades especificadas y externas a la actividad en sí, pero vinculadas a la actividad de estudiar de manera empírica o experiencial (estudiar se convierte en actividad instrumental especificada, porque podemos estudiar para robar, para hacer amigos, para ayudar a otro, para educarse, etcétera).

Cada una de estas categorías de actividad común (interna y externa) es, a su vez, susceptible de especificaciones; cada una de ellas puede ser usada para lograr finalidades externas vinculadas experiencialmente con la actividad. En conjunto dan cuenta de la actividad humana con rigor lógico. Desde la perspectiva del lenguaje común, de un padre no experto en educación, nos damos cuenta de que influimos en el educando propiciando actividades comunes internas y externas para educar. A la hora de estudiar, hacemos que lean, pero educar no es estudiar un tema o leer un texto. A la hora de jugar, buscamos la oportunidad de adquirir hábitos y que se diviertan, pero divertirse jugando no es sin más educar y, por si eso fuera poco, además, podemos divertirnos con cosas reprochables y podemos generar hábitos indeseables; y así sucesivamente con cada actividad que hayamos seleccionado. Es un hecho que las actividades comunes se usan propedéuticamente para finalidades educativas, pero también pueden usarse para otras finalidades. Las actividades comunes pueden ser usadas para realizar actividades especificadas instrumentales y tienen valor propedéutico; son preparatorias para algo posterior. Y esto es así, por una parte, porque todo lo que usamos como medio en una relación mediofin, adquiere la condición propia de los medios en la relación (el medio es lo que hacemos para lograr el fin y el fin es un valor elegido como meta en la relación medios-fines) y, por otra parte, es así, porque el medio muestra su valor pedagógico en las condiciones que le son propias, ajustando el medio al agente, a la finalidad educativa y a la acción, en cada circunstancia. Todos los medios adquieren propiedades de versatilidad, reversibilidad, reemplazabilidad y recursividad, y por esas propiedades los medios se convierten en condiciones singulares del sentido pedagógico de estos: un medio sirve para diversas finalidades, pero cualquier medio no es igualmente bueno para cualquier fin, ni para cualquier sujeto (versatilidad); en cada circunstancia, un determinado medio puede ser sustituido por otro en determinadas condiciones (reemplazabilidad); los medios son limitados pero aportan soluciones recursivas que descargan las carencias y superan, de alguna manera, las limitaciones, son medios finitos, pero permiten soluciones infinitas (recursividad); un medio es un fin mientras no se ha conseguido y una vez conseguido es un medio para otro fin (reversibilidad). En palabras de Dewey:

Todo medio es un fin temporal hasta que lo hayamos alcanzado. Todo fin llega a ser un medio de llevar más allá a la actividad, tan pronto como se ha alcanzado. Lo llamamos fin, cuando señala la dirección futura de la actividad a que estamos dedicados; medio, cuando indica la dirección presente. Todo divorcio entre el fin y los medios disminuye la significación de la actividad (1971, p. 118). 

UNA APROXIMACIÓN DESDE LA PERSPECTIVA MESOAXIOLÓGICA

\section{EstUdiar SE AJUSTA AL PRINCIPIO DE ACTIVIDAd}

Hablar de la actividad en educación supone reconocerla como principio, es decir, que en la actividad hay un carácter especial que debe estar presente del mismo modo en los resultados, en las tareas específicas y en la función del educador. Para la pedagogía activa, este carácter consiste en la necesidad de tener presente, tanto en las tareas educativas, como en los resultados, como en la función docente, que el educando no es un mero paciente-marioneta de la acción del educador, ni un simple agente-actor que quiere los cambios que el educador propone y se responsabiliza con voluntad de cumplirlos, sino que tiene que llegar a ser también agente-autor de los cambios que en sí mismo se producen.

La importancia de la actividad es un hecho innegable en la pedagogía contemporánea. Si hubiera que resumir con una sola frase la pedagogía contemporánea, al menos en su ideal más claro y universalmente formulado, posiblemente tendríamos que considerar la pedagogía de la actividad como la nueva frontera educativa.

Desde la perspectiva de la actividad común interna podemos decir que la actividad es principio de la educación, porque nadie se educa sin hacer actividad común. Nadie se educa sin estar pensando, sintiendo, queriendo, pensando, operando, proyectando y simbolizando creadoramente. Nos educamos por medio de la actividad común externa, estudiando, jugando, trabajando, indagando-explorando, interviniendo y relacionándonos con el yo, el otro y lo otro. Nos educamos, en primer lugar, usando esa actividad para lograr metas educativas que responden a necesidades socio históricas específicas en cada orientación formativa temporal con objeto de desarrollar la condición humana individual, social, histórica y de especie. Pero nos educamos fundamentalmente, porque, al mejorar nuestra capacidad de pensar, sentir, querer, elegir-hacer u operar, decidir-actuar o proyectar y construircultura-simbolizando o crear, mejoramos nuestra posibilidad de ser actor y autor de nuestros actos. Por tanto, nos educamos, no solo por un uso propedéutico e instrumental, para educar, de la actividad de estudiar, sino porque, al utilizar la actividad externa para educarnos, ponemos en marcha el uso de la actividad interna común y la mejoramos. Dicho de otro modo, para estudiar bien y educarme, estudiando, tengo que tener activas las capacidades comunes internas de pensar, sentir, querer, operar, proyectar y crear, usándolas para el fin propio de estudiar. Y eso quiere decir que al estudiar mejoramos y entrenamos la actividad común interna sin la cual no es posible educar y por eso podemos decir de manera radical que la raíz de la cuestión pedagógica es que estudiar como actividad en sí educa, porque, al estudiar, mejoramos y entrenamos las actividades-capacidades internas que hacen posible que el educando sea agente actor y cada vez mejor agente autor de su propios proyectos y actos.

Así mismo, en Pedagogía, hablar de la actividad como principio no significa atender sólo a la actividad. No se sigue la posición pendular frente a la pasividad. El principio de actividad no quiere decir simplemente que realizamos actividades, es 
JOSÉ MANUEL TOURIÑÁN LÓPEZ

ESTUDIAR ES ACTIVIDAD COMÚN EXTERNA Y SIEMPRE EDUCAMOS CON LA ACTIVIDAD. UNA APROXIMACIÓN DESDE LA PERSPECTIVA MESOAXIOLÓGICA

decir, tareas propias de la educación, porque esto es no decir nada. Pero tampoco quiere decir simplemente pedagogía de la acción cuyo resultado es la propia acción. Lo que se defiende con la actividad como principio de educación no es favorecer el sentir, pensar o elegir, por el puro hecho de sentir, pensar o elegir, sino que interesan esas actividades como principios de los que proceden los resultados educativos (Touriñán, 2014).

El activismo vendría a defender el carácter educativo de la acción por la acción, o lo que es lo mismo, bastaría con que el alumno haga voluntariamente algo para que se eduque. Pero esta postura es rechazable porque confunde la acción voluntaria con la acción educativa y nos lleva a defender exclusivamente la acción del educando, cuando lo que procede no es la negación de la actividad del educador, sino la conveniencia de que, correlativa a la acción controlada del educador, se dé la acción en el educando.

La actividad está presente en toda educación: desde una perspectiva, como principio de intervención y, desde otra, como principio de educación. Y precisamente por ser esto así, se explica que la actividad se convierta en el principio-eje vertebrador de la educación y represente el sentido real de la educación como actividad dirigida al uso y construcción de experiencia valiosa para generar actividad educada. Usamos la actividad común para educar, educamos las competencias adecuadas de la actividad común y esperamos obtener actividad educada. En definitiva, usamos la actividad de manera controlada para lograr actividad educada y educar la actividad por medio de las competencias adecuadas (Touriñán, 2015).

El principio de actividad, ni es pasividad, ni es activismo; es uso de la actividad de manera controlada para actuar educadamente. Y de este modo, la actividad y el control son principios de la intervención pedagógica, derivados de la condición de agente que tiene que construirse a sí mismo y reconocerse con el otro y lo otro en un entorno cultural diverso de interacción, por medio de los valores que ha de elegir, comprometerse, decidir y realizar, ejecutando por medio de la acción concreta lo comprendido e interpretado de la relación medio-fin, expresándolo, de acuerdo con las oportunidades.

En perspectiva mesoaxiológica, las actividades comunes internas son el principioeje vertebrador de la dinámica en la educación: si tenemos actividad común interna (pensar, sentir, querer, operar, proyectar y crear) y esa actividad es la que se activa para educarse, debemos intervenir sobre las dimensiones humanas genéricas de esas actividades. Hablamos de dimensiones en la persona haciendo referencia a la extensión del criterio de decisión que delimita la dimensión como tal. En educación y respecto de la actividad interna común, hablamos de dimensiones generales de intervención para referirnos a aquello que está en el hombre y hace posible esas diferentes actividades.

Cuando hablamos de las competencias adecuadas, relacionamos cada dimensión general de intervención con la actividad interna correspondiente (pensar-razonar 
/ sentir-tener sentimientos / querer / elegir-hacer / decidir-proyectar/ crear simbolizando). Las dimensiones generales de intervención son inteligencia, afectividad, voluntad, operatividad, proyectividad y creatividad.

La extensión del criterio en cada dimensión es la actividad con la que se vincula. En la dimensión general 'inteligencia', la extensión de criterio de decisión es la actividad de pensar; en la dimensión general de 'afectividad', la extensión de criterio es sentir y tener sentimientos; en la dimensión general 'voluntad', la extensión de criterio es querer; en la dimensión general 'operatividad', la extensión de criterios es operar, obrar, actuar libremente, relacionar medios-fines, construir procesos; en la dimensión general 'proyectividad', la extensión de criterio es la decisión moral, integrar medios-fines en proyectos decididos, construir proyectos y metas; en la dimensión general 'creatividad', la extensión de criterio es construir cultura, interpretando la realidad con signos y símbolos, crear es construir simbolizando (no, crear de la nada, que está fuera de lo humano, pero sí construir cultura).

Todas las dimensiones son importantes e imprescindibles; no hay mayor o menor importancia de una de ellas en lo humano; sin cualquiera de ellas se está incompleto como humano y no es posible realizar la acción; todas tienen que ejecutarse, respetando el significado de la relación educativa en tanto que educativa.

\section{ESTUDIAR EDUCA COMO ACTIVIDAD AL HACER FACTIBLE LA CONCORDANCIA ENTRE VALORES Y SENTIMIENTOS EN EL PASO DEL CONOCIMIENTO A LA ACCIÓN}

Intervenimos para establecer una relación educativa que logre educar y para ello utilizamos la actividad del educando y del educador. La relación educativa es el foco de la función de educar en la que se produce la interacción entre yo, el otro y lo otro. Y precisamente por eso, desde la perspectiva de la relación educativa, la interacción de identidades, la relación con el otro es un componente definitorio en la educación. Respecto de nosotros mismos y de los demás, en los procesos de auto y heteroeducación, tenemos que lograr en la relación educativa el paso del conocimiento a la acción y ello exige lograr una puesta en escena en la que la concordancia valores-sentimientos se produzca: elegir, comprometerse, decidir y realizar tienen que tener su concordancia en la acción concreta en actitudes de reconocimiento, aceptación, acogida y entrega a la tarea y al logro, respectivamente.

Desde la perspectiva del conocimiento de la educación, es obligado que pensemos en la relación educativa como una forma de interacción singular y distinta, cuyo significado orienta el uso de las actividades comunes a la finalidad de educar y a los criterios de significado de educar. Transformamos información en conocimiento y éste en educación ajustándolo a criterios de significado de educar y ello exige, de acuerdo con los rasgos de carácter que determinan el significado de educación, que pasemos del conocimiento a la acción, por medio de la relación educativa y de la intervención pedagógica, afectando a todas las dimensiones generales de 
intervención identificadas en la persona educando como actividad común interna (Touriñán, 2016).

El paso del conocimiento a la acción que se busca en cada relación educativa singular requiere interacción con el educando para que logre la concordancia entre valores y sentimientos, porque ese es el camino pedagógico para lograr que el educando realice algo (Touriñán, 2014). Yo puedo elegir hacer algo, puedo comprometerme con ese algo y puedo decidir integrar ese algo como parte de mis proyectos, pero, a continuación, tengo que realizarlo, debo pasar del pensamiento a la acción, debo pasar del valor realizado y realizable a la efectiva realización. Y esto implica, en la ejecución de la acción, interpretación, comprensión y expresión. No hay educación sin afectividad, es decir, sin afrontar el problema de generar experiencia sentida del valor. Y para ello necesitamos hábitos operativos, volitivos, proyectivos, afectivos, cognitivos y creativos. La efectiva realización de la acción requiere hábitos operativos, volitivos y proyectivos, pero, además, necesitamos hábitos afectivos, cognitivos y creativos. Y solo de ese modo llegamos a la realización de la acción que siempre implica en la ejecución de la acción, interpretación, comprensión y expresión (integración cognitiva, simbolizante-creadora y afectiva). La realización exige ejecutar mediante la acción lo comprendido e interpretado, expresándolo. Y la acción concreta se especifica como actividad común externa de juego, trabajo, estudio, indagación, intervención y relación, según el caso. Y esto se aplica a la acción del educador y a la acción del educando en la relación educativa, atendiendo a la distinción entre conocer, enseñar y educar.

La efectiva realización de algo exige generar experiencia sentida del valor. La efectiva realización de la acción requiere hábitos operativos, volitivos y proyectivos, pero, además, necesitamos hábitos afectivos, cognitivos y creativos. Y solo de ese modo llegamos a la realización de la acción que siempre implica ejecución, interpretación y expresión (integración comprensivo-cognitiva, interpretativa-creadora y afectiva). Realizar requiere concordar valores y sentimientos.

Por medio del sentimiento manifestamos el estado de ánimo que se ha producido por cumplir o no nuestras expectativas en la acción; manifestamos y esperamos reconocimiento de nuestra elección; manifestamos y esperamos aceptación de nuestro compromiso voluntario; manifestamos y esperamos acogida nuestros proyectos y manifestamos entrega a ellos. Elegir, comprometerse, decidir y sentir positivamente un valor, tiene su manifestación afectiva de vinculación y apego, en actitudes de reconocimiento, aceptación, acogida y entrega a la acción. Lo que caracteriza a la actitud es su condición de experiencia significativa de aprendizaje nacida de la evaluación afectiva de los resultados positivos o negativos de la realización de una determinada conducta, bajo la forma de relación compleja valor-actividad común interna del educando, concordando valores y sentimientos en el paso del conocimiento a la acción: 

UNA APROXIMACIÓN DESDE LA PERSPECTIVA MESOAXIOLÓGICA

Por consiguiente, veo la relación educativa, ni más, ni menos, como el ejercicio de la educación y ello implica asumir la complejidad propia de la educación y que he sistematizado en un triple eje condicional: la condición fundamentante del valor en la educación, la doble condición de agente actor y autor y la concurrencia de conocimiento y acción en cada intervención. Esta triple condición debe cumplirse en cada caso concreto de la relación educativa, porque desde la complejidad se fijan los rasgos que determinan realmente el significado de 'educativo' y permiten singularizar la relación respecto de otros tipos de relaciones. Si no se cumplen esos rasgos de significado que caracterizan a 'educación', la relación educativa será genéricamente relación, pero no podrá ser específicamente educativa, porque no lograría caracterizarse frente a otras relaciones. Debemos asumir que (Touriñán, 2019b):

- en la relación educativa se crea una vinculación entre valor y elección, de manera que, al operar, podemos mejorar el sentido responsable de acción, en cumplimiento del carácter axiológico de la educación, construyendo procesos desde la relación medios-fines:

- en la relación educativa se crea una vinculación entre valor y obligación, de manera que, al querer, podemos mejorar el compromiso voluntario de acción, en cumplimiento del carácter personal de la educación, estableciendo nuestro compromiso personal con la acción;

- en la relación educativa se crea una vinculación entre valor y decisión, de manera que, al decidir, podemos mejorar el sentido de vida individualizado que tiene esa acción, en cumplimiento del carácter patrimonial de la educación, construyendo metas;

- en la relación educativa se crea una vinculación de apego o dependencia entre valor y sentimiento de manera que, al sentir afectivamente y expresar lo sentido, podemos orientarnos hacia el logro de experiencia sentida del valor por medio de la integración afectiva, en cumplimiento del carácter integral de la educación;

- en la relación educativa se crea una vinculación entre ideas y creencias con las expectativas y convicciones, por medio de las formas de pensamiento, de manera que, al comprender-, somos capaces de integrar cognitivamente los valores pensados y creídos con la realidad, en cumplimiento del carácter gnoseológico de la educación;

- en la relación educativa se crea una vinculación entre signos y significados, de manera que, al interpretar la situación, somos capaces de hacer integración creativa del valor por medio de símbolos, en cumplimiento del carácter espiritual de la educación, y darle significado a la condición humana en el mundo simbolizado, construyendo cultura; 
- en la relación educativa se crea una vinculación entre categorías de espaciotiempo-género-diferencia específica, respecto de la relación entre el yo, el otro y lo otro en cada acto educativo, de manera que, al interaccionar, somos capaces de mantener en cada intervención el sentido territorial, duradero, cultural y formativo de la educación.

En la relación educativa, por tanto, buscamos la concordancia valores-sentimientos en cada interacción y para ello elegimos, nos comprometemos, decidimos y realizamos lo decidido. Y para realizar, ejecutamos mediante la acción lo comprendido e interpretado, expresándolo. La realización exige ejecutar mediante la acción. Y esa acción, además de la actividad común interna del sujeto, requiere la actividad común externa del educando. Realizamos por medio del juego, del trabajo, del estudio, de la indagación-investigación-exploración, de la intervención en cada acto y de la relación que se establezca entre el yo y las cosas usadas en la relación definida siempre como relación yo-el otro-lo otro. Todo esto es visto por el educador en la relación educativa como medios. Y esto se aplica directamente a la actividad de estudiar porque en tanto que la ejercemos, buscamos la concordancia entre valores y sentimientos para dar el paso del conocimiento a la acción.

\section{CONCLUSIONES}

Estudiamos para educarnos, porque estudiar es actividad propedéutica y nos educamos al ejecutar la actividad de estudiar, porque estudiar es actividad común externa ajustada al principio de actividad; nos educamos con la actividad en sí, al ejecutarla.

Estudiamos para educarnos significa que la actividad de estudiar es propedéutica y preparatoria para lograr educación. Como actividad propedéutica es una actividad instrumental especificada y puede ser utilizada para educar y para otras muchas finalidades: hacer un amigo, ayudar a otro, robar, hacerse una profesión, preparar un examen y así sucesivamente.

Cuando se domina una actividad instrumental especificada, su dominio genera un plus, porque la herramienta abre nuevas posibilidades creativas que pueden estar orientadas a educar o a otras metas. Unas nuevas posibilidades se abren por medio de la actividad aprendida y una clase diferente de competencia cobra vida; la competencia hace un uso creativo de la actividad, igual que la actividad conforma el desarrollo de la competencia.

Además, como actividad en sí, estudiar tiene su propia meta vinculada conceptualmente a la actividad y la identifica. Estudiamos para saber y dominar el objeto de estudio; sin la meta de saber o dominar el tema, no hay actividad de estudiar propiamente dicha, estudiar es, por tanto, una actividad común externa.

Estudiar como actividad propedéutica y como actividad en sí es susceptible de intervención pedagógica y de intervención educativa, para cumplir la meta, para 
mejorar la actividad que implica y para explicar y comprender la actividad como resultado de una actividad intencional que se realiza en procesos de auto y heteroeducación y también como acontecimiento sometido a complejos circunstanciales de necesidad y suficiencia.

En Pedagogía, por principio de actividad, se sabe que la actividad de estudiar como actividad común externa, al ser ejecutada, activa la actividad común interna del agente. No se puede estar estudiando sin estar pensando, sintiendo, queriendo, operando, proyectando e interpretando creativamente lo que hacemos. Al estudiar, se entrena y mejora la actividad común interna sin la cual no es posible educar. Por tanto, nos educamos al ejecutar la actividad de estudiar.

Además, nos educamos al estudiar, porque la actividad común externa requiere que el agente pase del conocimiento a la acción, pase del valor de la actividad realizable a la efectiva realización de ese valor, ejecutando la acción. Para ello, hay que establecer la concordancia entre valores y sentimientos que es objetivo de la relación educativa en cada interacción. Se trata de conseguir actitudes de reconocimiento, aceptación, acogida y entrega al valor de la actividad a realizar. Y desde esta perspectiva, la actividad de estudiar, al ejecutarse, pasando del conocimiento a la acción, es un modo sólido y confirmado de practicar y mantener y mejorar la relación entre valor-elección, valor-obligación, valor-decisión, valor-sentimiento, valor-pensamiento y valor-creación que hay que lograr para educar. Y eso, que es lo que se hace gracias a la relación educativa que establecemos en cada intervención, permite afirmar que, al estudiar, nos educamos, ejecutando la acción.

\section{REFERENCIAS BIBLIOGRÁFICAS}

Bell, D. (1976). El advenimiento de la sociedad posindustrial. Madrid: Alianza.

Botkin, J. W., Elmandjra,M., y Malitza,M. (1979). Aprender, horizonte sin límites. Madrid: Santillana. https://doi.org/10.1080/02103702.1980.10821815

Bruner, J. (2009). Actos del significado. Más allá de la revolución cognitiva. Barcelona: Paidós. Bruner, J. (2010). El habla del niño. Aprendiendo a usar el lenguaje. Barcelona: Paidós. $8^{a}$ reimp. Carbonell, J. et al. (2000). Pedagogías del siglo XX. Barcelona: Cisspraxis.

Carbonell, R. G, (1988). Estudiemos sin esfuerzo. Madrid: Edaf.

Carbonell, R. G. (1989). Lectura rápida para todos. Madrid: Edaf.

Château, J. (Dir.) (1956). Les grands pedagogues. Paris: P.U.F.

Claxton, G. (2001). Aprender. El reto del aprendizaje continuo. Buenos Aires: Paidós.

Colom, J. y Touriñán, J. M. (2008). La lectura en el siglo XXI, en SITE, Lectura y educación. Barcelona: Universidad autónoma de Barcelona. Recuperado de: http://www.ucm.es/ info/site/docu/26site/actas26site.pdf (Consultado el 29/09/2011).

Cranach, M. V. y Harré, R. (1982). The Analysis of Action. Cambridge: Cambridge University Press. Damasio, A. (2010). Y el cerebro creó al hombre. Barcelona: Destino.

Decroly, O. (1929). Problemas de psicología y de pedagogía. Madrid: Beltrán. 
JOSÉ MANUEL TOURIÑÁN LÓPEZ ESTUDIAR ES ACTIVIDAD COMÚN EXTERNA Y SIEMPRE EDUCAMOS CON LA ACTIVIDAD. UNA APROXIMACIÓN DESDE LA PERSPECTIVA MESOAXIOLÓGICA

Delors, J. (1996). La Educación encierra un tesoro. Madrid: Santillana-Unesco.

Dewey, J. (1929). La ciencia de la educación. Buenos Aires: Losada.

Dewey, J. (1971). Democracia y educación. Buenos Aires: Losada.

Dewey, J. (1998). Cómo pensamos. Nueva exposición de la relación entre pensamiento reflexivo y proceso educativo. Barcelona: Paidós.

Díaz Barriga, F. (2006). Enseñanza situada. Vinculo entre la escuela y la vida. México: McGrawHill.

DRAE (2013). Diccionario de la lengua española. Madrid: Real Academia Española. http:// lema.rae.es/drae/

Dray, W. (1957). Laws and Explanation in History. Oxford: Oxford University Press.

Elam, S. (Ed.) (1973). La educación y la estructura del conocimiento. Investigaciones sobre el proceso del aprendizaje y la naturaleza de las disciplinas que integran el currículum. Buenos Aires: El Ateneo.

Elvin, H. L. (1973). La educación y la sociedad contemporánea. Barcelona: Labor.

Elzo, J. Andrés, F. González-Anleo, J. González Blasco, L. Laespada, M. T. y Salazar, L. (2003). Jóvenes españoles 2003. Madrid: Fundación Santa María.

Esteve, J. M. (2010). La tercera revolución educativa. La educación en la sociedad del conocimiento. Madrid: Paidós.

Faure, E. (1973). Aprender a ser. Madrid: Alianza.

Ferrater, J. (1979). De la materia a la razón. Madrid: Alianza.

Ferrater, J. (1980). Diccionario de filosofía. Madrid: Alianza.

Ferrer Guardia, F. (1912). La escuela moderna. Póstuma explicación y alcance de la enseñanza racionalista. Barcelona: Tusquets.

Freinet, C. (1978). Las invariantes pedagógicas. Barcelona: Laia.

García Carrasco, J. (2007). Leer en la cara y en el mundo. Barcelona: Herder.

García Carrasco, J. (2012). Diagnóstico: tristeza; tratamiento: alimentar preguntas vigorosas. En F. Gil y D. Reyero (Coords.), Homenaje a J. A. Ibáñez-Martín (pp.103-127). Madrid: Biblioteca Online.

Guiton, J. (2019). El trabajo intelectual: consejos a los que estudian y a los que escriben. Madrid: Rialp.

Hallak, J. (2003). Globalización, derechos humanos y educación. En L. Núñez y C. Romero, Evaluación de políticas educativas. VIII Congreso nacional de Teoría de la Educación (pp. 127-142). Madrid: OEI-SITE.

Harré, R. y Secord, P.F. (1979). The Explanation of Social Behaviour. Oxford: Basil Blackwell. Hernández, P. y García, L. (1991). Psicología y enseñanza del estudio. Madrid: Pirámide.

Husén, T. (1978). La sociedad educativa. Madrid: Anaya.

Husén, T. (1985). Nuevo análisis de la sociedad del aprendizaje. Barcelona: Paidós.

Luzuriaga, L. (1968). Pedagogía social y política. Buenos Aires: Losada.

Mackie, J. L. (1965). Causes and Conditions. American Philosophy Quarterley, 2(4), 245-264.

Marc-Wogau, K. (1962). On Historical Explanation. Theoria, (28), 213-233. https://doi. org/10.1111/j.1755-2567.1962.tb00323.x

Marín Ibáñez, R. (1973). Principios de la educación contemporánea. Madrid: Rialp. 

UNA APROXIMACIÓN DESDE LA PERSPECTIVA MESOAXIOLÓGICA

Martín, E. (2007). Leer para comprender y aprender. Madrid: CEPE.

Mialaret, G. (1979). Introducción a la pedagogía. Barcelona: Planeta.

Montessori, M. ${ }^{a}$ (1937). El método de la pedagogía científica. Barcelona: Araluce.

Morin, E. (2000). Los siete saberes necesarios a la educación del futuro. Venezuela: UNESCOIESALC. Universidad Central de Venezuela.

Morin, E. (2002). ¿Una segunda mundialización? En E. Morín, R. Petrella, George, S. Naïr, V. Pérez-Díaz, I. Ramona y E. Trías (Eds.) Desafíos de la Mundialización (pp. 25-39). Madrid: Fundación M. Botín.

Mosterín, J. (1978). Racionalidad y acción humana. Madrid: Alianza Universidad.

Mosterín, J. (2009). La cultura humana. Madrid: Espasa Calpe.

Neira, T. R. (2011). Hacia una nueva civilización. Los muros de la escuela y el asedio de los bits. Oviedo: Universidad de Oviedo.

Nieto García, A. (1980). Adaptación de la juventud al cambio científico. De juventud, 3, 143-153.

Ortega y Gasset, J. (1968). Sobre el estudiar y el estudiante, en su obra, Misión de la Universidad. Madrid: Alianza.

Palacios, J. (1979). La cuestión escolar. Análisis y perspectivas. Barcelona: Laia.

Peters, R. S. (1958). The Concept of Motivation. Londres: Routledge and Kegan Paul.

Piaget, J. (1977). Biología y conocimiento. Madrid: Siglo XXI.

Piaget, J. (1980). Psicología y Pedagogía. Barcelona: Ariel.

Piaget, J. y Inhelder, B. (1972). Psicología del niño. Madrid: Morata.

Pieper, J. (2108). El ocio y la vida intelectual (pensamiento actual). Madrid: Rialp.

Pinillos, J. L. (1978). Lo físico y lo mental. Boletín Informativo de la Fundación Juan March, (71), 3-31

Pinker, S. (2007). El mundo de las palabras. Una introducción a la naturaleza humana. Barcelona: Paidós.

Pinker, S. (2011). Cómo funciona la mente. Barcelona: Destino.

Robinson, F. P. (1970). Efective Study. New York: Harper and Row.

Rousseau, J.-J. (1973). Emilio o la educación. Barcelona: Fontanella.

Sánchez, M. ${ }^{a}$ L. (1991). Cómo estudiar. Madrid: Granada.

SI(e)TE (2012). Creatividad, educación e innovación: emprender la tarea de ser autor y no sólo actor de sus propios proyectos. Revista de Investigación en Educación, 10(1), 7-29.

SI(e)TE (2016). Repensar las ideas dominantes en la educación. Santiago de Compostela: Andavira.

SI(e)TE (2018). La Pedagogía, hoy. Santiago de Compostela: Andavira.

SI(e)TE (2019). Saberpara hacer en educación. Santiago de Compostela: Andavira (en prensa).

Staton, Th. F. (1996). Cómo estudiar. México: Editorial Trillas.

Taylor, R. (1966). Action and Purposse. New Jersey: Prentice Hall.

Tierno, B. (2003). Las mejores técnicas de estudio. Madrid: Temas de Hoy.

Toffler, A. (1976). El schock del futuro. Barcelona: Plaza y Janés.

Toffler, A. (1980). La tercera ola. Barcelona: Plaza y Janés. 
Touriñán, J. M. (1981). Valor pedagógico y educativo del principio de actividad. Revista española de pedagogía, 39(153), 127-142.

Touriñán, J. M. (1986). Delimitación pedagógica de estudiar y estudiante. Revista Ciencias de la Educación, 32(128), 433-454.

Touriñán, J. M. (1987). Teoría de la Educación. La educación como objeto de conocimiento. Madrid: Anaya.

Touriñán, J. M. (1996). Análisis conceptual de los procesos educativos formales, no formales e informales. Teoría de la Educación. Revista Interuniversitaria, (8), 55-80.

Touriñán, J. M. (1997). La racionalización de la intervención pedagógica: explicación y comprensión. Revista de Educación, (314), 157-186.

Touriñán, J. M. (1999). Informe sobre el valor de las nuevas tecnologias para la mejora de la calidad de la docencia universitaria. Proyecto USC. 2002. Santiago de Compostela: Universidad de Santiago.

Touriñán, J. M. (2004). La educación electrónica: un reto de la sociedad digital en la escuela. Revista Española de Pedagogía, 62(227), 31-56.

Touriñán, J. M. (2005). Educación electrónica e innovación estratégica. El reto de la sociedad digital en la escuela. Santiago de Compostela: Xunta de Galicia.

Touriñán, J. M. (2009). La escuela entre la permanencia y el cambio. Revista de Ciencias de la Educación, (218), 127-150.

Touriñán, J. M. (2013). Conocer, enseñar y educar no significan lo mismo. El carácter y el sentido de la educación como referentes de su significado desde la mirada pedagógica. Teoría de la Educación. Revista Interuniversitaria, 25(1), 25-46.

Touriñán, J. M. (2014). Dónde está la educación. Actividad común interna y elementos estructurales de la intervención. A Coruña: Netbiblo.

Touriñán, J. M. (2015). Pedagogía mesoaxiológica y concepto de educación. Santiago de Compostela: Andavira.

Touriñán, J. M. (2016). Pedagogía general. Principios de educación y principios de intervención. A Coruña: Bello y Martínez.

Touriñán, J. M. (2017). Mentalidad pedagógica y diseño educativo. De la pedagogía general a las pedagogías aplicadas en la función de educar. Santiago de Compostela: Andavira.

Touriñán, J. M. (2018). Concepto de educación y conocimiento de la educación. The Concept of Education and the Knowledge of Education. Colombia-Nueva York: Redipe (BowkerBooks).

Touriñán, J. M. (2019a). Pedagogía de las artes. La perspectiva mesoaxiológica. Santiago de Compostela: Andavira (en prensa).

Touriñán, J. (2019b). La relación educativa es un concepto con significado propio que requiere concordancia entre valores y sentimientos en cada interacción. Sophia, colección de Filosofía de la Educación, 26(1), 223-279. https://doi.org/10.17163/soph.n26.2019.07

Touriñán, J. M. y Longueira, S. (Coords.) (2018). La construcción de ámbitos de educación. Pedagogía general y aplicada. Santiago de Compostela: Andavira.

Touriñán, J. M. y Sáez, R. (2015). La mirada pedagógica. Teoría de la educación, metodología y focalizaciones. Santiago de Compostela: Andavira. 
Touriñán, J. M. y Soto, J. (2005). El programa e-Europa y la educación electrónica: el desarrollo de la sociedad de la información como objetivo de la Unión Europea. Tecnología y Comunicación Educativas (41), 34-58.

Trilla, J. (Coord.) (2001). El legado pedagógico del siglo XX para la escuela del siglo XXI. Barcelona: Graó.

Vera, J. y Esteve, J. M. (Coords.) (2001). Un examen a la cultura escolar ¿Sería usted capaz de aprobar un examen de secundaria? Barcelona: Octaedro.

Von Wright, G. H. (1979). Explicación y comprensión. Madrid: Alianza Universidad.

Von Wright, G. H. (1980). El determinismo y el estudio del hombre. En J. Manninen y R. Toumela (Comps.), Ensayos sobre explicación y comprensión (pp. 183-204). Madrid: Alianza Universidad.

Wright, L. (1976). Teleological Explanations. An Etiological Analysis of Goals and Functions. Los Angeles: University of California Press.

Yela, M. (1978). Herencia y ambiente en la Psicología contemporánea. Boletín Informativo de la Fundación Juan March, (76), 3-25. 